\title{
Nuevo Comité Editorial
}

\author{
New Editorial Committee
}

REVISTA ARGENTINA DE CIRUGÍA PLÁSTICA 2019;25(2):52. HTTPS://DOI.ORG/10.32825/RACP/201902/0052-0052

Estimados colegas

Le damos la más cordial bienvenida, en nombre de toda la Comisión Directiva, a la Dra. Georgia Martínez y a su Comité de redacción en esta nueva etapa a cargo de la revista de la Sociedad Argentina de Cirugía Plástica, Estética y Reparadora.

Nuestra revista cuenta con artículos científicos con los temas más relevantes de nuestra especialidad y constituye un pilar fundamental en la divulgación del conocimiento y la educación médica continua, permitiendo una actualización a todos sus lectores. La elaboración de la misma requiere de esfuerzo por parte de los editores y permite difundir los conocimientos y experiencia de los autores.

Cuando se publica un artículo original en una revista científica se hace un aporte al conocimiento. Por ello los invitamos a participar activamente publicando sus trabajos y experiencias en nuestra revista para consolidarla como el más importante medio escrito de la especialidad a nivel nacional.

Agradecemos especialmente a todos los que han sido editores y autores de nuestra revista que con su esfuerzo y aporte científico contribuyeron a difundir el conocimiento de nuestra especialidad.

Saludamos atentamente.

Dr. Raúl Tolaba

Secretario de la Revista Argentina de Cirugía Plástica

Dr. Juan Carlos Rodríguez

Presidente de la Revista Argentina de Cirugía Plástica 